\title{
O HISTÓRICO DO MOVIMENTO ESTUDANTIL PARANAENSE SECUNDARISTA POR MEIO DA MEMÓRIA
}

\author{
Alexandre Felipe Fiuza \\ Universidade Estadual do Oeste do Paraná \\ alefiuza@terra.com.br \\ Ana Karine Braggio \\ Universidade Estadual do Oeste do Paraná \\ anakarinebraggio@hotmail.com \\ Silvana Lazzarotto Schmitt \\ Instituto Federal do Paraná - campus de Irati \\ sillazzarotto@hotmail.com
}

\begin{abstract}
RESUMO
Este artigo busca contribuir na reconstrução da história do movimento estudantil paranaense secundarista, recorrendo a entrevistas realizadas pelos autores com ex-militantes do período ditatorial brasileiro (1964-1985), bem como aquelas publicadas em meios impressos. Partindo de fontes memorialísticas, documentais e bibliográficas, abordamos casos de estudantes que foram presos e perseguidos pela polícia política e por outros órgãos repressivos, analisando o período a partir de suas impressões. Com base em reflexões que problematizam as particularidades da história do tempo presente, da história oral e da memória, este texto analisa os testemunhos que conformam um contraponto às narrativas oficiais, contribuindo para a produção histórica sobre o tema.
\end{abstract}

Palavras-chave: Memória. Movimento estudantil secundarista. Ditadura.

\section{THE HISTORY OF THE SECONDARY PARANAENSE STUDENT MOVEMENT BY MEMORY}

\begin{abstract}
This article seeks to contribute to the reconstruction of the history of the secondary student movement of Paraná, using interviews conducted by the authors with ex - militants of the Brazilian dictatorial period (1964-1985), as well as those published in printed media. From memorial, documentary and bibliographical sources, we deal with cases of students who were arrested and persecuted by the political police and other repressive organs, analyzing the period from their impressions. Based on reflections that problematize the particularities of the history of the present time, oral history and memory, this text analyzes the testimonies that conform a counterpoint to the official narratives, contributing to the historical production on the theme.
\end{abstract}

Keywords: Memory. Secondary student movement. Dictatorship.

\section{EL HISTORICO DEL MOVIMIENTO ESTUDIANTIL PARANAENSE SECUNDARIO DESDE LA MEMORIA}

\section{RESUMEN}


Este artículo intenta contribuir con la reconstrucción de la historia del movimiento estudiantil paranaense secundario, recorriendo a entrevistas realizadas por los autores con ex militantes del período dictatorial brasileño (1964-1985), así como aquellas publicadas en los medios impresos. Desde fuentes memorísticas, documentales y bibliográficas, abordamos casos de estudiantes presos y perseguidos por la policía política y por otros órganos represivos, analizando el período desde sus impresiones. Con base en reflexiones que problematizan las particularidades de la historia del tiempo presente, de la historia oral y de la memoria, este texto analiza los testimonios que conforman un contrapunto a las narrativas oficiales, contribuyendo para la producción histórica sobre el tema.

Palabras clave: Memoria. Movimiento estudiantil secundario. Dictadura.

\section{L'HISTOIRE DU MOUVEMENT DES ÉLÈVES DE L'ÉTAT DE PARANÁ DU SECONDAIRE À TRAVERS LA MÉMOIRE}

\section{RÉSUMÉ}

Cet article a pour but de contribuer à la reconstruction de l'histoire du mouvement étudiant du secondaire du Paraná, en utilisant des entretiens menés par les auteurs avec d'anciens militants de la période dictatoriale brésilienne (1964-1985), ainsi que ceux publiés dans les médias imprimés. Avec l'utilisation de sources mémorielles, documentaires et bibliographiques, nous traitons des cas d'étudiants qui ont été arrêtés et persécutés par la police politique et d'autres organes répressifs, analysant la période à partir de leurs impressions. À partir de réflexions qui problématisent les particularités de l'histoire du temps présent, de l'histoire orale et de la mémoire, ce texte analyse les témoignages en contrepoint des récits officiels, contribuant à la production historique sur le thème.

Mots-clés: Mémoire. Mouvement étudiant du secondaire. Dictature.

\section{INTRODUÇÃO}

Os órgãos responsáveis pelo aparato repressivo brasileiro funcionaram nos diferentes estados, sendo frequentemente vinculados às Secretarias de Segurança Pública, desde princípios da década de 1920 até o final da ditadura militar. Há que se destacar, entre estas forças de repressão, as Delegacias ou Departamentos de Ordem Política e Social (DOPS). Além de lidarem com os chamados "crimes comuns", também eram responsáveis pela repressão, prisão e produção de informações do campo político e social. No que concerne ao seu modus operandi, tinham como uma de suas precípuas finalidades a produção de informações sobre o inimigo político, ao longo dos diferentes períodos históricos, nos cerca de 60 anos de sua existência. Quando a documentação angariada por estes órgãos, no processo de investigação e censura, supunha ou comprovava se tratar de atividades subversivas, a esfera subjetiva desta repressão era acionada, ou seja, passava-se da informação à ação policial, prendendo, cassando, por exemplo, suas licenças de funcionamento para os estabelecimentos, deportando os 
estrangeiros, destruindo bens individuais e amedrontando estas pessoas através de perseguições políticas. Um dos materiais produzidos pela polícia foi justamente os depoimentos destas pessoas consideradas subversivas, colhidos muitas vezes sob tortura, ou passíveis de fabulação dos depoentes para evitar novas prisões ou desmantelamento de organizações políticas. A partir da ditadura civil-militar, instaurada em 1964, os castigos repressivos se avolumaram, chegando à repressão física, caracterizada por prisões ilegais e por atos de tortura (PÁDUA; GAMA, 1998, p. 31-32).

A partir dos processos repressivos estatais, da discussão sobre a memória de militantes estudantis secundaristas, da história da educação, do patrimônio histórico-educativo, da metodologia que envolve a história oral e da análise do período que abarca a ditadura, este artigo analisa as impressões e ressignificações produzidas pelos líderes estudantis ao refletirem sobre este passado recente. A reconstrução dessa história, aqui entendida a partir da dimensão da história do tempo presente, deve ser estabelecida pelo sentido que determinados acontecimentos produziram nas gerações contemporâneas, caracterizando a amplitude e diversidade de informações coletadas (ARÓSTEGUI, 2006, p. 492). Por conseguinte, a história oral contribui sobremaneira para a reconstrução destas memórias de sujeitos que foram violentados por torturas, violências físicas e psicológicas, e que viveram na clandestinidade ou no exílio. Tomados enquanto testemunhos históricos, se caracterizam como ricos contrapontos à história oficial e à história de espectro mais macro, estabelecendo um debate em torno da memória e da consciência histórica do período ditatorial.

Nessa produção de sentidos advinda da história oral, não há como não se estabelecer sua relação com o conceito de memória, que é fundamental como um referente a mais para a construção do passado, produzindo leituras deste a partir de dimensões individuais, mas que se relacionam com identidades ou perspectivas coletivas. Portanto, estas leituras e mesmo releituras do passado, a partir da perspectiva testemunhal, revelam impressões e interpretações nem sempre alcançáveis pelas fontes mais tradicionais utilizadas na pesquisa histórica. Por conseguinte, trazem do passado a informação que alcança as múltiplas dimensões do cotidiano e os efeitos produzidos pelas estruturas sociais e econômicas do período histórico em apreço. Uma característica comum às diferentes ditaduras que assolaram o mundo ocidental no século $\mathrm{XX}$, é que se conformam como regimes que, ainda durante sua existência, buscavam ocultar suas políticas autoritárias de Estado por meio da repressão política e pela censura. Nestes contextos, a memória é essencial como contraponto: 
de representação do passado fundamental para a constituição das identidades coletivas, com base em características diferenciais que a definem e a distinguem de outras maneiras de relatar esse passado, e fundamentalmente da história. (LVOVICH; BISQUERT, 2008, p. 7, tradução livre). ${ }^{1}$

Assim como os eventos do passado são retomados por novas produções historiográficas, emanando as novas perguntas e novas questões que vão sendo trazidas pela contemporaneidade, também as impressões do passado, trazida pelos testemunhos, vão igualmente se ressignificando, o que não deve ser tomado como um problema, mas como um elemento de análise a mais para compor a leitura do passado. Ainda que reconhecendo a validade da história oral, alguns autores indicam algumas fragilidades, pois:

\begin{abstract}
São conhecidas as artimanhas da memória. Imersa no presente, preocupada com o futuro, quando suscitada, a memória é sempre seletiva. Provocada, revela, mas também silencia. Não raro, é arbitrária, oculta evidências relevantes, e se compraz em alterar e modificar acontecimentos e fatos cruciais. Acuada, dissimula, manhosa, ou engana, traiçoeira. Não se trata de afirmar que há memórias autênticas ou mentirosas. Às vezes, é certo, é possível flagrar um propósito consciente de falsificar o passado, mas mesmo neste caso o exercício não perde o valor porque a falsificação pode oferecer interessantes pistas de compreensão do narrador, de sua trajetória e do objeto recortado. (REIS; RIDENTI; MOTTA, 2004, p. 29).
\end{abstract}

Apesar destas ressalvas, que abarcam as dicotomias entre a subjetividade e a objetividade na história oral, concordamos com as premissas trazidas pela argentina Beatriz Sarlo (2005, p. 62): “A confiança nos testemunhos das vítimas é necessária para a instalação de regimes democráticos e o estabelecimento de um princípio de reparação e justiça" ${ }^{2}$. Como também assevera outra pesquisadora, dos testemunhos sobre a violência de Estado não é adequado esperar uma narrativa histórica abrangente e globalizante, pois: "Não dá conta mais do que esta experiência e não teria porque ser diferente: este é seu sentido. O testemunho atesta a partir de sua presença no lugar dos acontecimentos [...] das vítimas” (CALVEIRO, 2008, p. 221, tradução livre) ${ }^{3}$. Como base desta reflexão, igualmente consideramos a memória objetivada um horizonte a ser almejado e procurado, como bem destaca Julio Aróstegui (2006).

É fundamental reconhecer a validade das narrativas presente nestes testemunhos, pois o ato mesmo de rememorar igualmente revela a urdidura de tecer novas intepretações do passado, dialogando com aquele que entrevista. Rememorar também decorre de uma reflexão

\footnotetext{
1 "Pero también la noción de memoria es de primordial importancia porque la misma se ha constituido en un importante objeto de reflexión intelectual, que la considera una forma de representación del pasado fundamental para la constitución de las identidades colectivas, en base a características diferenciales que la definen y la distinguen de otras maneras de relatar ese pasado, y fundamentalmente de la historia." (LVOVICH; BISQUERT, 2008, p. 7).

2 "La confianza en los testimonios de las víctimas es necesaria para la instalación de los regímenes democráticos y el arraigo de un principio de reparación y justicia" (SARLO, 2005, p. 62).

3 "No da cuenta más que de esa experiencia y no tendría por qué hacerlo; ése es su sentido. El testigo atestigua desde su presencia en el lugar de los acontecimientos [...] de las víctimas” (CALVEIRO, 2008, p. 221).
}

Rev. Iberoam. Patrim. Histórico-Educativo, Campinas (SP), v. 5, p. 1-21, e019013, 2019 
histórica e de uma ação deliberada de se re-situar no passado, compartilhando as reminiscências e reavaliando o lugar do sujeito que fala neste processo histórico. Ao discutir a memória e suas particularidades, Raphael Samuel afirma que

[...] longe de ser meramente um receptáculo passivo ou um sistema de armazenagem, um banco de imagens do passado, é, isto sim, uma força ativa, que molda; que é dinâmica - o que ela sintomaticamente planeja esquecer é tão importante quanto o que ela lembra - e que é dialeticamente relacionada ao pensamento histórico, ao invés de ser apenas uma espécie de seu negativo. (SAMUEL, 1997, p. 44).

Portanto, esta relação ativa com a recordação é atravessada pelas dinâmicas mais diversas, inclusive, em cada retorno ao passado, o narrador pode lembrar-se de outras passagens raramente ou nunca lembradas. Como expressões de processos de objetivações e de construções argumentativas, algumas vezes, até mesmo em falas deliberadamente fabuladas, ainda assim sustentam uma potência como expressões do passado que se busca abolir, atenuar ou até mesmo falsear. No que concerne aos depoimentos destes militantes estudantis, ao se cotejar suas falas com outros documentos, esta perspectiva, digamos, falseadora, não foi observada. Há, mesmo, uma concatenação entre narrativas individuais e a produção historiográfica e memorialística sobre o tema. Isso não impede de reconhecermos, por sua vez, que determinadas passagens destas memórias podem não ter sido recordadas, seja pelo sofrimento que elas podem trazer, ou pelas contradições inerentes às experiências humanas que elas podem suscitar.

Como atesta Alessandro Portelli (2010, p. 20), há também uma relação, digamos, dialógica, entre entrevistador(a) e entrevistado(a), uma vez que "enquanto o pesquisador olha para o narrador, o narrador olha para ele, a fim de entender quem é e o que quer, e de modelar seu próprio discurso a partir dessas percepções”. Afinal, "a história oral é um gênero multivocal, resultado do trabalho comum de uma pluralidade de autores em diálogo".

Outra discussão que se torna pertinente quando o objeto de estudo está inscrito no recorte temporal mais contemporâneo, diz respeito ao debate sobre a História do Tempo Presente, uma vez que os estudos com esta perspectiva ganharam fôlego a partir do final do século passado e encontrou ressonância nas pesquisas históricas relativas aos regimes ditatoriais e das guerras. A utilização da teoria do tempo presente consubstancia uma forma de analisar a realidade que permite ao historiador/pesquisador valer-se de fontes históricas mais contemporâneas e inovadoras, só possíveis de serem examinadas em função, justamente, da proximidade histórica dos eventos analisados. Destaca-se, ainda, como bem caracterizou o advento da História dos Annales, no final da década de 1920, a possibilidade de novamente valer-se da interdisciplinaridade na operação historiográfica, porque se trata: 
[...] de uma proposta que sendo plenamente historiográfica só pode, no entanto, trabalhar no limite da disciplina, com uma necessária inclinação à interdisciplinaridade, com métodos que devem ser necessariamente novos e na ausência de alguns determinantes básicos da visão histórica vigente como é a determinação cronológica. A HDP não é, obviamente, nem um momento cronológico, nem um setor historiográfico, mas uma proposta de fazer História que não é passado mas presente. (ARÓSTEGUI, 2006, p. 241).

Por fim, o objeto deste artigo se inscreve no campo da história da educação, uma vez que traz ao debate como os agentes históricos reagiram às políticas de Estado, tanto mais gerais, como aquelas relativas ao campo educacional, consolidadas pela legislação, censura, repressão, produção de informações e imposição de pretensos consensos sociais. Visamos ainda a preservação do patrimônio histórico-educativo uma vez que a documentação oficial, ainda que eivada de uma leitura oficial e propositalmente direcionada a favor do poder autoritário, caracteriza-se como um rico manancial de fontes históricas para o campo da história da educação. Como se circunscreve ao período ditatorial, paradoxalmente, é na documentação oficial que se podem encontrar memórias, documentos e vestígios da militância e da perseguição a estudantes, professores e professoras. Nestes acervos, inclusive, estão presentes documentos produzidos pelo movimento estudantil e docente que já não são encontrados em outros acervos públicos ou particulares, uma vez que reter tais registros no período da ditadura era produzir provas contra si mesmo.

Ainda ao que concerne ao patrimônio histórico-educativo, acresça-se o fato de que a realização de entrevistas com os protagonistas do movimento estudantil é igualmente produzir novas fontes, preservando e dando luz às memórias. Afinal, futuramente, estas entrevistas podem ser reunidas num banco de memórias do movimento estudantil ou compor acervos dos museus históricos e pedagógicos. Por conseguinte, considerando a potência inerente à história oral, apresentamos a seguir parte da história do movimento estudantil secundarista paranaense, bem como alguns aspectos do movimento estudantil nacional, a partir do olhar daqueles que nele atuaram, uma vez que não é possível compreender o regional descolado do movimento nacional. Enfim, num período de revisionismo da história e da ascensão de interpretações históricas deslocadas e desfocadas do passado, e não unicamente no Brasil, cabe àqueles(as) que se valem das pesquisas históricas, incluídos aqui os historiadores e historiadoras da educação, cultivarem o rigor e o compromisso ético na escrita da história:

\footnotetext{
A historiografia - ou seja, a história como narração, disciplina ou gênero possuindo suas regras, suas instituições e os seus procedimentos - não pode [...] substituir-se à memória coletiva nem criar uma tradição alternativa que possa ser compartilhada. Mas a dignidade essencial da vocação histórica permanece, e o seu imperativo moral parece-me ter hoje em dia mais urgência do que nunca. No mundo que é o nosso não se trata mais de uma questão de decadência da memória coletiva e de declínio da
} 
consciência do passado, mas sim da violação brutal daquilo que a memória ainda pode conservar, da mentira deliberada pela deformação das fontes e dos arquivos, da invenção de passados recompostos e míticos a serviço de poderosos tenebrosos. (YERUSHALMI, 1988, p. 19 apud SELIGMANN-SILVA, 2003, p. 62-63).

\title{
MEMÓRIA DO MOVIMENTO ESTUDANTIL SECUNDARISTA (1964-1985)
}

Com base em entrevistas produzidas pelos autores deste trabalho e em entrevistas publicadas em fontes jornalísticas, bibliográficas e sites (como o site oficial da UNE - União Nacional dos Estudantes, que organizou uma coleção de entrevistas no ano de 2008), busca-se, aqui, compor um quadro do movimento estudantil secundarista a partir das impressões de seus militantes, com ênfase nos aspectos inerentes a organização estudantil paranaense. Convém destacar que utilizaremos pseudônimos para tratar dos militantes por nós entrevistados, os militantes citados por meio das outras fontes (jornal, livros, sites), terão seus nomes mantidos tal qual apresentados nas publicações consultadas, devidamente citadas.

Iniciamos nossa análise com uma entrevista concedida ao portal Estudantenet, site oficial da UNE e da UBES (União Brasileira de Estudantes Secundaristas), por Apolinário Rebelo, que foi presidente da UBES, no ano de 1983. Essa entrevista faz parte da série de matérias realizadas em comemoração aos 25 de reconstrução da entidade, e aos 58 anos de sua fundação, completados em julho de 2006. O depoimento é relevante ao descrever um histórico do movimento e ao apontar elementos da reorganização dos estudantes secundaristas em escala nacional, uma vez que não há como entender a dinâmica estadual alheia ao contexto nacional. Apolinário Rebelo assevera:

\begin{abstract}
A UBES foi fundada em 25 de julho de 1948 e ficou na legalidade até $1^{\circ}$ de abril de 1964, quando passou a funcionar na clandestinidade, após ter a sua sede no Rio de Janeiro, na Rua do Catete, número 132, queimada e destruída pela ditadura. A entidade permaneceu na ilegalidade até o início 1985, quando houve a posse do Presidente [José] Sarney. Ele sancionou a lei de autoria do deputado Aldo Arantes que legalizou as entidades estudantis. Esse período de 21 anos de ilegalidade foi muito ruim para a democracia e para os estudantes, que ficaram sem representação e voz na sociedade e nas escolas. Foi muito ruim também para as lideranças estudantis, brutalmente perseguidas e, muitas delas, mortas. A UBES foi uma entidade fundamental para a democracia do país. Sempre foi importante neste aspecto, de mobilizar os jovens em defesa da melhoria do país, principalmente, no que diz respeito à educação. Mas também estávamos antenados com o debate político, o debate sobre a economia, porque sabíamos que, sem a participação política dos jovens, o país poderia ficar na estagnação. (REBELO, 2006, n.p.).
\end{abstract}

Como se observa, neste fragmento, o entrevistado recupera uma cronologia relativa ao movimento estudantil secundarista, incluindo em suas impressões pessoais uma narrativa comum aos líderes estudantis. Observamos, também, no depoimento de Rebelo, que há uma 
assertiva no sentido de que os estudantes se organizariam unicamente por meio da instituição de nível nacional, a UBES, mas, na sequência de nossas pesquisas, demonstramos que, mesmo sem a possibilidade de diálogo direto com a representação nacional, os estudantes secundaristas se organizaram regionalmente e realizaram inúmeras atividades durante o período da ditadura civil-militar.

Em outra entrevista concedida ao portal Estudantenet (apud CINTRA; MARQUES, 2009, p. 226), pelo ex-presidente Delcimar Pires, que teve seu mandato em 1984, havia naquela altura a necessidade de reorganizar os estudantes, como ele mesmo descreve: “[...] o nosso trabalho era quase que integralmente realizar reuniões, passeatas, caminhadas, para divulgar e atrair a atenção da juventude à necessidade de se organizar”, porém, as dificuldades para organização eram grandes "as viagens eram sempre uma dificuldade, a maioria de ônibus de São Paulo a Mato Grosso do Sul, ou Brasília, etc. Poucas vezes tínhamos passagens aéreas, geralmente com apoio de governos estaduais saídos das eleições de 82 - São Paulo, Paraná, Rio de Janeiro, Goiás, etc. [...]” (PIRES, 2006 apud CINTRA; MARQUES, 2009, p. 226).

Além disso, o exercício de censura e repressão, obrigava muitos movimentos estudantis, como os grêmios, por exemplo, a mascarar práticas políticas, tanto de direita como de esquerda, dificultando ainda mais suas ações de reorganização. Destaca-se que as DOPS, historicamente, também vigiavam movimentos de extrema direita. Portanto, o exame da documentação oficial produzida pela DOPS do Estado do Paraná, revela que parte do movimento estudantil, tantas vezes tomado de forma romântica como naturalmente de esquerda, também podia se identificar com a ditadura e com seus ideários, servindo como freio às iniciativas inerentes às oposições ao governo.

Milton Ivan Heller, em seu livro intitulado Resistência Democrática: a repressão no Paraná, evidencia, através de entrevistas realizadas com ex-militantes do movimento estudantil paranaense universitário, que houve forte repressão e tortura contra muitos estudantes. Dentre os depoimentos obtidos pelo autor, fazemos referência a um fragmento da fala do presidente da UPE (União Paranaense dos Estudantes) na gestão 1967/8, Stênio Sales Jacob, que se refere ao congresso da UNE em Ibiúna, onde todos os líderes nacionais foram presos pela polícia, fato que somado ao Ato Institucional $n^{\circ} 5$ tornou quase impossível a reorganização e reestruturação do movimento:

Acabamos sendo condenados no processo realizado em São Paulo pela participação no congresso da UNE. E o julgamento foi uma farsa: dentro da sala de audiências havia 22 elementos da Policia Militar, armados de metralhadora. A rua em frente à auditoria foi bloqueada e só era permitida a presença no auditório de um membro da família de cada estudante, sentado no banco dos réus. O constrangimento era tal que 
nossos advogados não tinham nem condições de fazer uma defesa que pretendiam. Disso resultou a pena de um ano de prisão, juntamente com centenas de estudantes de todo o país, incluindo alguns companheiros do Paraná. Ficamos os dois primeiros meses na prisão do Ahu e fomos transferidos para São Paulo, onde ficamos seis meses, cumprindo o resto da pena em Curitiba. (JACOB apud HELLER, 1988, p. 291).

Observamos, nesse fragmento da entrevista, as características inerentes à polícia política durante a ditadura militar, que, assim como nas demais regiões do país, no estado do Paraná foram alvo da repressão política inúmeros opositores, como intelectuais, estudantes, dirigentes sindicais e militantes políticos que não concordavam com as ações impostas pelo governo militar. Acresça-se à lista de vítimas, aquelas pessoas acusadas de crimes políticos, mas que não participavam de nenhum movimento político, mas que acabavam sendo também vítimas da sanha dos militares. Em função da necessidade de produção de novas provas, inúmeros presos políticos estavam a mercê da ditadura, sendo inúmeras vezes transferidos entre as estruturas da repressão, inclusive clandestinas, visando a incriminação judicial, ou a trágica execução destas pessoas. Havendo ou não provas do crime político, a maioria dos detidos era interrogada sob torturas físicas e/ou psicológicas.

Sobre esta construção do inimigo, é esclarecedor o relato do ex-presidente da UPE sobre sua prisão e a busca da polícia por provas incriminatórias que pudessem ser usadas contra ele e outros envolvidos:

\footnotetext{
Quando estive preso em São Paulo, vi muita gente ser torturada. Quando me transferiram de Curitiba para São Paulo, a primeira noite eu passei no DOI-CODI, em uma cela onde já havia uns quarenta presos políticos. E cada vez que a porta abria era mais um que seria torturado. Felizmente eu estava sob a guarda da Justiça Militar e escapei dos horrores que aconteciam nas chamadas prisões de verificação. Mas vi ali no Presídio Tiradentes muitos companheiros chegarem arrebentados, vindos do DOPS ou do DOI-CODI. Dezenas de pessoas, entre estudantes, trabalhadores e profissionais liberais, passavam quatro, cinco meses incomunicáveis, aguardando que qualquer fato pudesse inseri-los em uma situação que os comprometesse (JACOB apud HELLER, 1988, p. 298).
}

Portanto, não era unicamente tangível a dor das sevícias por qual passaram os presos políticos, mas também o desassossego trazido pela dúvida se seriam ou não os próximos e o sofrimento por ver seus companheiros e companheiras vítimas do terrorismo de Estado. Parte destes militantes conseguiu se safar da tortura física, uma vez que isto decorria de uma série de fatores, como a participação em algum grupo de oposição a ser desmantelado, por ser o elo para a caída de outros militantes, entre outros motivos.

A partir de outros depoimentos que foram coletados em 2007, por uma das autoras deste trabalho, podemos conhecer outras leituras deste processo vivido pelos militantes 
estudantis, como foi o caso do Militante $\mathrm{C}^{4}$. Este ex-militante do movimento estudantil paranaense esteve vinculado por mais tempo ao movimento universitário, mas também narrou algumas passagens sobre o movimento secundarista. Ele concluiu seus estudos no antigo Ensino Científico, que hoje podemos relacionar com o Ensino Médio, em Ponta Grossa, no Colégio Regente Feijó, onde acabou sendo diretor de Patrimônio do Centro Cívico, que, segundo ele, funcionava na prática como um grêmio estudantil do referido colégio. Ou seja, havia organização estudantil desde o início da década de 1960 também naquela região, portanto, antes do Golpe. Quando inquerido se teria ou não sido torturado, explicou: “As minhas prisões eram rápidas, de poucos dias, chamadas de prisões de averiguações e também para intimidar porque eu era o secretário do Partido Comunista no Movimento Estudantil, na União da Juventude Socialista, eu era organizador, era conhecido como Militante KGB” (MILITANTE C, 2007).

Outro depoimento coletado foi do Militante $\mathrm{N}^{5}$, integrante do movimento estudantil em Toledo, cidade do oeste do Paraná, no final da década de 1960, onde frequentou o Colégio La Salle e fez o ensino fundamental séries finais. O antigo ginásio cursou em $\mathrm{Castro}^{6}$, no Colégio Cristo Rei, e concluiu o ensino médio em Curitiba. Quando questionado se havia organização dos estudantes, particularmente em Toledo, afirmou:

Tinham, mas os grêmios eram muito poucos, o que tinha forte em Toledo era a UTES - União Toledana dos Estudantes Secundários. Ela tinha uma atividade, uma força até de inserção na sociedade boa. Então dos grêmios a moçada partia para participar da diretoria da UTES, para militar no movimento estudantil mais organizado, embora a UTES não fosse uma entidade de cunho político, muito mais esportiva, social. Mas claro que haviam a tendências de políticas no sentido de participar desta entidade, mas nada com uma ideologia definida. (MILITANTE N, 2010).

Podemos inferir que o movimento estudantil secundarista em Toledo se vinculava diretamente à UTES, mas que havia grêmios estudantis, embora não tão organizados como àquela, inclusive com uma atuação pouco articulada às discussões das questões sociais e políticas do período. Quando o Militante N, por sua vez, presidiu a UTES, como já tinha uma militância incipiente, tentou politizar a entidade, o que lhe pareceu uma tarefa árdua. Afirmou que os estudantes participaram de congressos estudantis, mas não havia uma articulação da entidade com no movimento estudantil universitário. Ao recordar-se de sua pré-adolescência no período do Golpe de 1964, asseverou:

\footnotetext{
${ }^{4}$ O Militante C é formado em Direito pela Pontifícia Universidade Católica do Paraná e, atualmente, exerce a profissão de advogado na cidade de Cascavel.

${ }^{5} \mathrm{O}$ militante $\mathrm{N}$ era jornalista no jornal $O$ Paraná, na cidade de Cascavel, quando concedeu a entrevista em 11 de junho de 2010. Todavia, faleceu no ano seguinte.

${ }^{6}$ Cidade paranaense onde Emília Ericksen teria criado o primeiro jardim de infância privado do Brasil, em 1862.
} 
Era uma situação muito difícil, mas essa situação difícil para nós não significava quase nada, porque éramos praticamente crianças, comecei a ter consciência política por volta dos meus 14/15 anos. Mas a grande maioria não estava nem aí, o país estava fervendo, pegando fogo e eles não sabiam de nada, não tinham interesse. Pelo contrário as histórias de Pra Frente Brasil, Transamazônica e Copa do Mundo eram assuntos muito mais correntes no meio estudantil do que a própria situação política. A não ser quando ela atingia, por exemplo, alguém da cidade. (MILITANTE N, 2010).

Portanto, este relato demonstra o que havíamos mencionado anteriormente: a articulação entre as memórias individuais com a construção de um enunciado que abarcasse as críticas posteriores ao período autoritário, como foi o caso do discurso do "Brasil grande" dos militares, que englobava vultosas obras públicas, e que se pautava em forte propaganda política do regime, já largamente trabalhada pela historiografia. Esta propaganda política, aliada à censura às artes, aos livros e aos meios de comunicação, se constituiu como um meio educativo informal, produzindo consensos sociais em torno da validade da ditadura e mesmo para ela imiscuir-se de responsabilidades pela situação econômica e social do país, além de ocultar o terrorismo de Estado imposto à oposição política. Por conseguinte, reafirmamos, estas falas são reatualizadas, o que bem caracteriza a história oral:

[...] um procedimento, um meio, um caminho para produção do conhecimento histórico. Traz em si um duplo ensinamento: sobre a época enfocada pelo depoimento - o tempo passado, e sobre a época na qual o documento foi produzido - o tempo presente. Trata-se, portanto, de uma produção especializada de documentos e fontes, realizada com interferência do historiador e na qual se cruzam intersubjetividades. (DELGADO, 2010, p. 16).

Outro depoimento relevante é o do ex-militante aqui denominado como Militante T, que forneceu informações sobre algumas características da organização dos estudantes paranaenses. O referido militante foi um dos fundadores do Grêmio Estudantil Castro Alves, do Colégio Wilson Joffre da cidade de Cascavel, em 1965. Também participou da ACES (Associação Cascavelense dos Estudantes Secundaristas) em 1968, no cargo de presidente da instituição e, posteriormente, foi membro da UPES (União Paranaense dos Estudantes Secundaristas), no ano de 1969.

Quando questionado sobre a forma como os estudantes secundaristas se organizavam para tomar decisões, relatou:

O pessoal lá era bem mais organizado do que agora, fazíamos o movimento com o objetivo de melhorar. Nós, por exemplo, não tínhamos uma cancha de esportes, não tínhamos nada de lazer, para realizar atividades nos intervalos e finais de semana. Então nós nos organizávamos e fazíamos as campanhas para comprar esses materiais. (MILITANTE T, 2010). 
Em seu relato, comentou o fato de os estudantes secundaristas de Cascavel atuarem nas campanhas eleitorais, apoiando candidatos a vereador e a prefeito. Tal fato possibilitava, segundo o Militante T, o apoio de políticos no sentido de contribuir para a organização dos estudantes, especialmente no Oeste do Paraná, tendo em vista que ele retoma o fato de que a cidade de Cascavel tinha uma atuação importante na organização dos estudantes paranaenses, destacando ainda a realização dos dois congressos estaduais na cidade, bem como outros acontecimentos que demonstram uma boa articulação dos estudantes secundaristas na região. Dentre eles, o fato de que o Grêmio Estudantil do Colégio Wilson Joffre conseguiu angariar fundos para a aquisição de materiais esportivos, auxílios para a construção de uma quadra esportiva e para a realização de concursos de oratória.

É importante destacar, segundo o depoimento de Militante T, que o Grêmio Estudantil Castro Alves foi devidamente registrado, com atas de criação. Com relação aos documentos, mais especificamente ao cuidado com essa documentação histórica do movimento estudantil paranaense, há uma grande lacuna de acervo. Uma breve pesquisa nas instituições estudantis da região e da capital nos possibilitou verificar que não houve interesse e nem cuidado em guardar esses documentos, que poderiam agora traduzir, de forma mais rigorosa, a história da organização estudantil no Paraná. Quando entramos em contato com o presidente da UPE durante a gestão 2011-2013, questionamos a existência de um histórico da instituição que no mínimo abrangesse os nomes dos líderes, porém a entidade nada possui, nem mesmo atas de reuniões deste período estudado. As fontes documentais encontradas foram aquelas disponibilizadas por algumas das pessoas entrevistadas, outra parte, no arquivo da DOPS do Paraná. Isso também poderia ser explicado pelo medo em ser portador de documentos considerados "subversivos", no caso dos movimentos de esquerda.

Militante $\mathrm{T}$ destaca que todas as cidades participavam dos congressos estaduais e que eram organizadas caravanas de estudantes. Os congressos eram relevantes porque, além de discutirem temas pertinentes à organização dos estudantes, eram ainda o espaço para a realização da escolha da próxima diretoria.

Ainda de acordo com o Militante T (2010), quando questionado sobre a ação da polícia política com relação aos estudantes, ele recorda que "não podiam fazer muito barulho, era o tempo do AI-5, que pegava os estudantes", assim qualquer ação estudantil era observada.

Destacamos ainda um depoimento do escritor aqui denominado de Militante $\mathrm{E}^{7}$, no qual relata que, em 1964, estava cursando o quarto ano na Escola Adventista de Cascavel, e que

\footnotetext{
${ }^{7}$ Depoimento concedido a uma das autoras, via e-mail, em junho de 2010.
} 
seu pai, um jornalista que exercia militância política clandestina, entrou na clandestinidade para evitar ser preso. Ele iniciou sua militância estudantil na cidade de Foz do Iguaçu, quando:

No Colégio Monsenhor Guilherme, em Foz, travei conhecimento com estudantes paraguaios, filhos de exilados, e argentinos, com os quais fiz uma amizade internacionalista inesquecível. Ali comecei a militância no movimento estudantil, apoiando para a diretoria do grêmio escolar a chapa que me pareceu mais progressista. Como a eleição foi no segundo semestre, o saldo dessa participação foi receber dos colegas argentinos a doação de livros impressos na URSS, em espanhol, com literatura marxista-leninista. (MILITANTE E, 2010).

Uma particularidade a ser destacada quanto à cidade de Foz do Iguaçu é sua condição de tríplice fronteira com Argentina e Paraguai, o que facilitava uma articulação estudantil de cunho internacional, inclusive pela facilidade de mobilidade pela fronteira. Por outro lado, esta região era considerada de interesse nacional durante a ditadura, o que também era prejudicial à organização política e sindical pelas ações desencadeadas pelos serviços de repressão e de inteligência destes três países, cujos períodos ditatoriais acabaram por coincidir cronologicamente.

Ao retornar à Cascavel, em 1966, o Militante E retornou aos estudos no conceituado Colégio público Wilson Joffre. Ele confirma aquilo que foi relatado por outro entrevistado, no caso, o Militante T, no que concerne ao fato de os estudantes secundaristas cascavelenses agirem de maneira bem articulada na altura, pois, nas palavras do Militante E,

Em 1968, de volta ao Colégio Wilson Joffre, ao lado de estudantes que vieram de Foz do Iguaçu e Porto União, passei a participar da oposição à diretoria da Associação Cascavelense dos Estudantes Secundários (Aces), que tinha uma longa tradição de combatividade no movimento estudantil. Luiz Picoli, que depois traiu os estudantes passando para a Arena, fez uma grande façanha na época. Cascavel comandava a luta estudantil secundarista no Paraná. (MILITANTE E, 2010).

O mesmo militante enfatiza o feito de Cascavel ter sediado a realização do COESES (Congresso Estadual dos Estudantes Secundaristas) de 1967, pois tal fato demonstrou a destacada articulação presente na organização estudantil dessa região. Relata ainda que um estudante cascavelense esteve à frente da entidade máxima de representação secundarista estadual e retomou alguns acontecimentos relativos ao XXIV COESES, realizado em Cascavel no ano de 1973:

O cascavelense Darlan Dallagnol foi por longo tempo presidente da UPES. Foi em Cascavel que pela primeira vez a UPES fez um megacongresso estudantil estadual. O local foi o Cine Teatro Coliseu. Um jornal publicou na ocasião uma charge em que um vendedor de doces gritou "Drops!", anunciando uma balinha muito procurada, e alguns estudantes correram apavorados para se esconder. DOPS era a famigerada Delegacia de Ordem Política e Social, que reprimia estudantes, professores, dirigentes sindicais, jornalistas, advogados e democratas em geral. Mas, como a duração maior 
do regime e seu endurecimento, essa estrutura de resistência passou ao controle de políticos da antiga Arena. Os líderes estudantis só podiam fazer bailinhos e mais nada. (MILITANTE E, 2010).

Ele destaca um fato histriônico relativo a uma charge que representa bem o "medo" dos estudantes em relação à DOPS, e tal receio não era infundado, como atestam os documentos e informações produzidas por esta polícia política, e também por suas ações violentas de repressão na rua e nas dependências das delegacias, onde grassavam as torturas físicas e psicológicas.

Ainda no tocante ao Colégio Wilson Joffre, o Militante E relata que em 1966 ocorreu a inauguração deste colégio e que aconteceram, no período, explosões em pontos variados da escola, como sinal de protesto contra a ditadura. No ano seguinte, em 1967, ele foi estudar na cidade de Buenos Aires, onde também atuou no movimento estudantil secundarista e participou de um grupo de estudantes, que ele caracterizou como sendo uma célula comunista. Destaca, todavia, que: "Dessas atividades só restam as lembranças, pois nada podia ser registrado, seja em ata, ou em anotações particulares, pois havia sempre o risco de queda. Pelo País todo, eram frequentes as notícias de prisões de militantes de esquerda.” (MILITANTE E, 2010).

A exemplo das ações que caracterizaram o Centro Popular de Cultura (CPC) da União nacional de Estudantes (UNE), o Militante E recorda que a militância se dava em meio a outras atividades que pudessem evitar suspeitas, como nas expressões artísticas:

Passei a me ligar aos integrantes do então MDB e criar um núcleo de estudantes revolucionários no Colégio Wilson Joffre. Utilizava a estratégia, recomendada por meu pai, de apresentar o grupo como um movimento literário, teatral e musical. Participei de concursos literários, escrevi peças de teatro e ao redor dessas atividades começamos a difundir a literatura marxista. (MILITANTE E, 2010).

Com seu retorno a Cascavel, o Militante E inscreveu uma chapa para concorrer à direção da ACES, a partir da militância partidária de oposição, junto ao Movimento Democrático Brasileiro (MDB),

Em 1969, organizamos uma chapa com a finalidade de concorrer à diretoria da ACES, com a participação de pessoas ligadas ao MDB e ao nosso grupo de estudantes revolucionários. Vencemos as eleições, contra todos os prognósticos. Como eu havia feito uma ação combativa e de tempo integral nessa luta, fui chamado pela direção eleita a assumir o Departamento de Comunicação da ACES. Como os demais dirigentes da ACES eram pessoas com empregos a zelar e estavam namorando para logo casar, a militância estudantil poderia levá-los a perder os empregos e arruinar a vida. Assim, passei a dirigir informalmente a ACES e a recrutar estudantes em diversos colégios para integrar as chapas concorrentes aos respectivos grêmios estudantis para tirá-los da direita, carola e fascista. (MILITANTE E, 2010). 
Este depoimento estabelece uma interessante relação entre as dinâmicas próprias da militância política e as injunções sociais e cotidianas que podiam dificultar as ações políticas, como o casamento ou o emprego. A história oral, ainda que aqui marcada por um depoimento escrito, é recorrente na exposição de situações cotidianas, nem sempre passíveis de serem analisadas a partir de outras fontes históricas. O campo cultural, mesmo com a repressão e a censura, continuou sendo uma força aglutinadora e catalizadora nestes movimentos:

Em 1970, montamos uma chapa exclusivamente revolucionária, apenas com alunos do Colégio Wilson Joffre, pois os pais dos alunos do nosso grupo em outras escolas não os permitiriam participar. Concorremos à ACES com uma chapa denominada Woodstock, referência ao festival de música e paz realizado no ano anterior nos EUA. O nome escondia a militância marxista, fazendo de conta que era pró-EUA, aceitável na época. Mas a plataforma ia mais além, embora dita apenas em sala de aula. Propunha a paz mundial, democracia no Brasil, liberdade de organização estudantil, o desenvolvimento artístico e cultural (na ACES já havíamos criado o Festival da Canção, Fercapo, depois encampado pelo Tuiuti Esporte Clube) e propúnhamos a criação do ensino superior. (MILITANTE E, 2010).

Nas entrelinhas deste depoimento percebemos que havia, sim, uma parcela de estudantes que estava à frente das instituições estudantis e que defendiam ou se simpatizavam com os ideais mais conservadores no campo da política.

\begin{abstract}
Nossa chapa foi derrotada naquela eleição de 1970, o que estava nas previsões. O importante era participar, organizar. E como nossas propostas foram encampadas pelo vencedor, Rogério Córdova, um democrata que uniu todos os colégios e depois seria presidente da UPES, ele nos chamou imediatamente para continuar participando da entidade. Todos nós integramos imediatamente às atividades e, mais uma vez, quando Córdova passou a ser um dirigente estadual, o Departamento de Comunicação passou a dirigir informalmente a ACES, em aliança com representantes do MDB. Eu praticamente morava na sede da ACES: fazia militância estudantil durante o dia, estudava à noite e após as aulas ia à sede da ACES para escrever notícias para a Rádio Colméia, jornal Diário do Oeste e depois para o jornal Fronteira do Iguaçu, que surgiu em 1971. (MILITANTE E, 2010).
\end{abstract}

Assim, só dois anos mais tarde conseguiram chegar ao seu objetivo. Ele relata que o grupo a que pertencia precisou a organizar-se de maneira a se infiltrarem na organização estudantil secundarista do Colégio Wilson Joffre de Cascavel, quando:

Em 1972, depois de várias tentativas, finalmente nosso grupo conseguiu se infiltrar no Centro Estudantil Castro Alves (CECA), do Colégio Wilson Joffre. Do CECA, sairíamos somente em 1974, após um atrito com o diretor da escola, Erly Fauth. Nessa época, já havíamos travado contato com o MR-8 e outros movimentos jovens de esquerda, ligados ao PCB ou suas dissidências. (MILITANTE E, 2010).

Em relação à entidade municipal, a ACES, os estudantes conseguiram ampliar seus canais de interlocução, ainda que tenha durado pouco tempo, como foi o caso de "[...] um programa na Rádio Colméia - A Voz do Estudante - que mais tarde nos foi tirado e entregue a 
estudantes ligados à antiga Arena. A Colméia então era a única emissora de rádio de Cascavel. Não havia TV" (MILITANTE E, 2010).

Outro militante estudantil que passou pelo mesmo Colégio Wilson Jofre foi aqui denominado de Militante $S^{8}$, onde, em 1974, foi membro do Grêmio Estudantil Castro Alves e da ACES, mas, diferente do entrevistado anterior, relatou que, por questões estratégicas, quando de sua participação na UPES, se aliaram ao governo militar, segundo ele, para evitar problemas com a DOPS e conseguir reorganizar o movimento secundarista, então afogado em dívidas. Assim, Militante S atuou no ME secundarista até 1979. De acordo com ele, os estudantes secundaristas paranaenses se organizaram, porque, naquele momento, a entidade de representação a nível estadual (UPES) estava desarticulada e com uma grande dívida financeira. Segundo ele, esta aproximação com a ditadura não era concordância com as políticas do regime, mas, acabaram por vincular-se ao partido oficial, a ARENA. Este rearranjo possibilitou contatos com o governador do Estado, Jaime Canet Junior, com a incumbência de que estes estudantes fundassem a Arena Jovem, ou seja, um braço do partido político dos militares.

O Militante S recorda o processo de organização dos COESES, quando, com cerca de uma semana de antecedência, pediam apoio do comércio e das pessoas que residiam na cidade para angariar fundos para a realização do Congresso. Uma lembrança que ele se reportou foi a visão preconceituosa que a sociedade tinha dos estudantes, com seus cabelos compridos, suas roupas extravagantes e um comportamento pouco aceito pela população mais conservadora. Apesar destes impasses, ele relata o grande potencial de articulação que os estudantes construíram no período:

\footnotetext{
A gente tinha uma organização enorme. Se hoje você for colocar mil, mil e quinhentos estudantes juntos você não consegue. E a gente debatia sobre todos os assuntos, e não tinha a cobertura da imprensa, pelo contrário a imprensa procurava esculhambar com a organização dos estudantes. (MIITANTE S, 2010).
}

Uma particularidade deste depoimento é que assim como há uma construção posterior sobre os desmandos da ditadura, aqui há uma perspectiva mais próxima da versão oficial relativa ao período autoritário. De certa maneira, há um processo de construção do relato do entrevistado, suavizando os efeitos do regime de força, e provavelmente aproximando sua visão da política atual em relação à militância da época.

\footnotetext{
${ }^{8}$ Depoimento realizado em 9 de março de 2010. No período residia em Cascavel e era responsável pela implementação do projeto da Câmara Municipal de Cascavel denominado "Câmara Jovem". Atuou no ME secundarista apenas a partir de 1974. Foi secretário da capital na gestão 1975/1976 da UPES.
} 
No depoimento concedido pelo Militante D, que militou no movimento secundarista paranaense já nos estertores da ditadura, no início da década de 1980, conseguimos vislumbrar mais um elemento crucial da organização estudantil paranaense, no caso, sua relação com entidades católicas. Ele destaca o fato de que as organizações que foram suprimidas pelo regime militar (como a JUC - Juventude Universitária Católica e a JOC - Juventude Operária Católica) foram sendo substituídas pelas Pastorais da Juventude e Operária, a nosso ver, contribuindo para a manutenção de uma prática religiosa mais alinhada à Teologia da Libertação. Ele também é oriundo do Colégio Wilson Jofre, concluindo o antigo segundo grau em 1982, onde participou, por um curto período, do grêmio estudantil, de onde migrou para a ACES. A diretoria desta entidade reunia estudantes de diferentes perspectivas políticas “[...] não era uma chapa com concepções unificadas. Tinha de tudo: gente sem partido, gente com partido e gente centro mais para direita" (MILITANTE D, 2010).

Por sua vez, o Militante D relembra o fato de que, nesse período, esteve em Cascavel o então presidente da República, João Figueiredo, acompanhado pelo governador do Paraná, Ney Braga. E que houve uma mobilização de alguns membros da ACES para tentar estabelecer contato com a comitiva do presidente, embora isso representasse apenas uma parte dos militantes que tinham uma concepção mais liberal da política.

A história da repressão política no Oeste e Sudoeste do Paraná ainda está sendo objeto de novas pesquisas acadêmicas e de trabalhos realizados por Comitês de Direitos Humanos da região. Expressão desta luta pela memória pode ser observada na realização da Audiência ${ }^{9}$ Pública da Comissão Estadual da Verdade do Paraná, realizada na Unioeste, campus de Cascavel, em março de 2014, que contou com testemunhos de cerca de vinte militantes que foram vítimas da violência dos órgãos de repressão da ditadura. A maior parte deles nunca havia falado em público sobre o que sofreram, trazendo narrativas pouco comuns, pois a maior parte da historiografia aborda os casos das vítimas geralmente oriundas da classe média e alta. Em sua maioria, eram camponeses de baixa renda, que no período pré-Golpe de 1964, se perfilaram aos ideais defendidos por líderes políticos como Leonel Brizola e seu Grupo dos Onze, ou ainda vinculados ao Partido Comunista Brasileiro, à Vanguarda Popular Revolucionária (VARPalmares), a VAR ou a Operação Três Passos. Acrescidos a estes depoimentos, também foram ouvidas lideranças e familiares de líderes indígenas assassinados durante a ditadura.

\footnotetext{
9 Mais informações, ver: SILVA, Carla Luciana; BATISTA, Alfredo. Combatentes: tempos de falar. Depoimentos da Audiência Pública da Comissão Estadual da Verdade do Paraná. Cascavel: Edunioeste, 2016.
}

Rev. Iberoam. Patrim. Histórico-Educativo, Campinas (SP), v. 5, p. 1-21, e019013, 2019 
Duas das vítimas na região em apreço, era um casal de professores da Escola Estadual Jorge Nacli, de Nova Aurora, quando, em maio de 1970, foram atingidos por uma operação militar que tinha como objetivo desarticular uma das bases da Vanguarda Armada Revolucionária (VAR/Palmares) ${ }^{10}$ na região. Luiz Andréa Fávero e Clari Isabel Dedavid Fávero, sendo que ele foi acusado de praticar atos terroristas e sequestros de diplomatas por meio do grupo guerrilheiro, ao passo que ela foi acusada de ter ministrado aulas subversivas. Ambos foram levados para o Batalhão de Fronteiras de Foz do Iguaçu, onde sofreram as mais diversas formas de tortura, desde pau-de-arara à choques elétricos (HAHN, 2008, p. 130).

Portanto, a história oral é também de fundamental importância para a escrita de um passado que foi ocultado e que depende dos testemunhos das vítimas (e mesmo dos algozes) para que a verdade, ou parte dela, seja reestabelecida.

\section{CONSIDERAÇÕES FINAIS}

Há inúmeras lacunas na história do movimento estudantil secundarista brasileiro. Parte destes hiatos decorre da própria realidade autoritária de então. Afinal, como afirmado anteriormente, ser portador de qualquer material destes coletivos era colocar em risco não só o estudante como aqueles do seu entorno. Muitas vezes, os relatos apontam que este material era destruído pelos militantes e até mesmo pelos pais destes para evitar possíveis flagrantes e produções de provas para a polícia política. Por outro lado, a disseminação do medo não era ilusória, pois os serviços de repressão e de vigilância minaram as bases dos estudantes organizados, seja em âmbito regional, como nacional. Por sua vez, as fontes históricas sobre o Movimento Estudantil se concentram precisamente nos depoimentos de seus militantes e, contraditoriamente, também nos materiais do movimento estudantil confiscados pela repressão política. Há nos arquivos públicos que alocam documentos das DOPS, por exemplo, um vasto material referente aos estudantes, como fotografias, informes de infiltrados, periódicos estudantis, textos de peças teatrais, poesias, manifestos e diversos documentos de análises de conjuntura e organizativos produzidos por eles, entre outros.

Fundamentais para compor um panorama do Movimento Estudantil secundarista, os depoimentos analisados possibilitaram conhecer a organização dos estudantes, quais foram suas

\footnotetext{
${ }^{10}$ Sobre outros casos de tortura e assassinatos que aconteceram no Estado do Paraná, ver: PALMAR, Aluízio. Onde foi que vocês enterraram nossos mortos? Curitiba: Travessa dos Editores, 2006. No livro, o autor, a partir das suas memórias de militante preso e torturado, resgata vários acontecimentos relacionados à esquerda brasileira, como o massacre contra militantes na região de Foz do Iguaçu, atraídos a uma emboscada, por um infiltrado pelos militares, quando voltaram clandestinamente do exílio.
} 
principais dificuldades e as particularidades dessa forma de militância no período. Por outro lado, também ajudam a explicar o enfraquecimento do Movimento Estudantil e as relações de parte destas organizações vinculadas ideologicamente à ditadura. De qualquer maneira, atestase que houve significativa movimentação das entidades de base durante quase todo o período ditatorial, como bem caracteriza o trabalho da UPES. Outro dado a se considerar é que, ao se examinar a militância estudantil em cidades como Cascavel ou Toledo, por exemplo, temos uma dinâmica aproximada com o que aconteceu em outras dezenas de cidades médias brasileiras. Afinal, inúmeras cidades interioranas, ainda que isoladas em relação aos grandes centros, foram testemunhas da agitação estudantil, como bem expressam os depoimentos e a documentação da vigilância política.

Estabelecendo uma relação com a atualidade, após um extenso período de refluxo das organizações estudantis ao longo das últimas duas décadas, percebe-se uma retomada dos movimentos estudantis, como bem expressou as ocupações das escolas públicas, entre 2015 e 2016. Estas ações coletivas dos estudantes revelaram que novas bandeiras e novas formas de atuar ganharam espaço, sendo significativo o protagonismo das mulheres e de pré-adolescentes, seja na direção dos movimentos, seja liderando núcleos que se constituíram também à revelia da estrutura organizativa clássica do movimento estudantil. Nestes atos estudantis, o ativismo cultural e político ganhou novos contornos e, de certa forma, estabeleceu uma ponte imaginária, e por vezes causal, entre as práticas desenvolvidas na década de 1960 e 1970 com as da atualidade, guardadas as respectivas particularidades históricas. Num momento de (re)ascensão de discursos e práticas fascistas, as experiências e histórias de luta destes e destas militantes são inspiradoras para a consecução de projetos de sociedades cada vez mais justas e solidárias, e, desta vez, também inclusivas, colocando novamente no cerne dos processos políticos e culturais o protagonismo da juventude estudantil.

\section{REFERÊNCIAS}

ARÓSTEGUI, Julio. A pesquisa histórica: teoria e método. Bauru - SP: Edusc, 2006.

CALVEIRO, Pilar. Testimonio y memoria en el relato histórico. In: RODRÍGUEZ, Ileana; SZURMUK, Mónica (Eds.). Memoria y Ciudadanía. Santiago do Chile: Editorial Cuarto Propio, 2008. p. 207-24.

CINTRA, André; MARQUES, Raisa. UBES Uma Rebeldia Consequente: A História do Movimento Estudantil Secundarista do Brasil. São Paulo: Ministério da Cultura, 2009. 
DELGADO, Lucília de Almeida Neves. História oral: memória, tempo, identidades. 2. ed. Belo Horizonte: Autêntica, 2010.

HAHN, Fábio André. Ditadura Militar e os órgãos de repressão: o caso de Nova Aurora/PR. III ENCONTRO DE PRODUÇÃO CIENTÍFICA E TECNOLÓGICA - EPCT. Anais eletrônicos. 2008. p. 130-131. Disponível em: http://www.fecilcam.br/nupem/index.php? option=com_content\&task=view\&id=15\&itemid=14. Acesso em: 27 set. 2018.

HELLER, Milton Ivan. Resistência democrática: a repressão no Paraná. Rio de Janeiro: Paz e Terra: Curitiba: Secretaria de Cultura do Estado do Paraná, 1988.

LVOVICH, Daniel; BISQUERT, Jaqueline. La cambiante memoria de la dictadura: discursos públicos, movimientos sociales y legitimidad democrática. Los Polvorines: Universidade Nacional de General Sarmiento, Buenos Aires: Biblioteca Nacional, 2008.

MILITANTE C. Depoimento oral. [31/03/2007]. Entrevistadora: Silvana Lazzarotto Schmitt. Cascavel, 2007.

MILITANTE D. Depoimento oral. [09/06/2010]. Entrevistadora: Silvana Lazzarotto Schmitt. Cascavel, 2010.

MILITANTE E. Depoimento escrito. [11/06/2010]. Entrevistadora: Silvana Lazzarotto Schmitt. Cascavel, 2010.

MILITANTE N. Depoimento oral. [19/06/2010]. Entrevistadora: Silvana Lazzarotto Schmitt. Cascavel, 2010.

MILITANTE S. Depoimento oral. [09/03/2010]. Entrevistadora: Silvana Lazzarotto Schmitt. Cascavel, 2010.

MILITANTE T. Depoimento escrito. [04/08/2010]. Entrevistadora: Silvana Lazzarotto Schmitt. Cascavel, 2010.

PÁDUA, Mônica; GAMA, Marcília. DOPS - do recolhimento ao acesso: o caso de Pernambuco. Quadrilátero: revista do arquivo público do distrito federal. Brasília, v. 1, p. 27 40, mar./ago. 1998.

PALMAR, Aluízio. Onde foi que vocês enterraram nossos mortos? 2. ed. Curitiba, PR: Travessa dos Editores, 2006.

PORTELLI, Alessandro. Ensaios de história oral. São Paulo: Letra e Voz, 2010.

REIS, Daniel Aarão; RIDENTI, Marcelo; MOTTA, Rodrigo Patto Sá. O golpe e a ditadura militar: quarenta anos depois (1964-2004). Bauru, SP: Edusc, 2004.

REBELO, Apolinário. Ubes, reorganizada há 25 anos, "é uma escola de democracia": depoimento. [20/08/2006]. Entrevistadores: EstudanteNet (UBES). São Paulo: Portal Vermelho, 2006. Entrevista concedida em comemoração aos 25 anos de reorganização da UBES. Disponível em: http://www.vermelho.org.br/meioambiente/noticia/6401-8. Acesso em 27 set. 2018. 
SAMUEL, Raphael. "Teatros da memória”. Projeto História, São Paulo, n. 14, 1997. p. 4181.

SARLO, Beatriz. Tiempo pasado: cultura de memoria y giro subjetivo. Una discusión. Buenos Aires: Siglo XXI, 2005.

SELIGMANN-SILVA, Márcio. Reflexões sobre a memória, a história e o esquecimento. In: SELIGMANN-SILVA, Márcio (org.). História, Memória, Literatura - Os testemunhos na Era das Catástrofes. Campinas, SP: Editora da Unicamp, 2003. p. 59-88.

SILVA, Carla Luciana e BATISTA, Alfredo. Combatentes: tempos de falar. Depoimentos da Audiência Pública da Comissão Estadual da Verdade do Paraná. Cascavel: Edunioeste, 2016.

Recebido em: 28 de setembro de 2018 Aceito em: 15 de abril de 2019 